\title{
Erratum to: Tumor necrosis factor beta NcoI polymorphism (rs909253) is associated with inflammatory and metabolic markers in acute ischemic stroke
}

\author{
Johnathan de Sousa Parreira • Ana Paula Kallaur • Marcio Francisco Lehmann • \\ Sayonara Rangel Oliveira • Daniela Frizon Alfieri • Francieli Delongui • \\ Maria Caroline Martins de Araújo • Carolina Rossato • Jessica Tavares de Almeida • \\ Larissa Muliterno Pelegrino • Erick Frank Bragato • Helena Kaminami Morimoto • \\ Andrea Name Colado Simão • Damacio Ramon Kaimen-Maciel • Edna Maria Vissoci Reiche
}

Published online: 23 August 2014

(C) Springer Science+Business Media New York 2014

Erratum to: Metab Brain Dis (2014)

DOI 10.1007/s11011-014-9584-6

Due to an oversight, Dr. Daniela Frizon Alfieri and Dr. Francieli Delongui's names were listed incorrectly (as Daniela Alfieri Frizon and Franceili Delongui, respectively) in the article Tumor necrosis factor beta NcoI polymorphism (rs909253) is associated with inflammatory and metabolic markers in acute ischemic stroke, Metab Brain Dis, July 2014, DOI 10.1007/s11011-014-9584-6.

The online version of the original article can be found at http://dx.doi.org/ 10.1007/s11011-014-9584-6 .

J. de Sousa Parreira · A. P. Kallaur • M. F. Lehmann · S. R. Oliveira ·

D. F. Alfieri $\cdot$ F. Delongui

Health Sciences Postgraduate Program, Health Sciences Center, State

University of Londrina, Londrina, Paraná, Brazil

M. F. Lehmann

Department of Clinical Surgery, Health Sciences Center, and

Neurosurgery Service of the University Hospital,

State University of Londrina, Londrina, Paraná, Brazil

M. C. M. de Araújo · C. Rossato · J. T. de Almeida •

L. M. Pelegrino • E. F. Bragato

Medicine Faculty, Health Sciences Center,

State University of Londrina, Londrina, Paraná, Brazil

H. K. Morimoto • A. N. C. Simão • E. M. V. Reiche $(\bowtie)$ Department of Pathology, Clinical Analysis, and Toxicology, Health Sciences Center, State University of Londrina, Av. Robert Koch, 60, 86.038-440 Londrina, Paraná, Brazil e-mail: reiche@sercomtel.com.br

D. R. Kaimen-Maciel

Department of Clinical Medicine, Health Sciences Center and Neurology Outpatient of the Outpatient Clinical Hospital,

State University of Londrina, Londrina, Paraná, Brazil 